\title{
Prevalence of Urogenital Schistosomiasis and its Implication on Control Efforts Among School Pupils in Ogun State, Southwest Nigeria
}

\author{
Susan I. Alexander ${ }^{1^{*}}$, Timothy S. Nwafor ${ }^{2}$, Pam V. Gyang ${ }^{2}$, Emmanuel T. Idowu', Olaolu- \\ wa P. Akinwale ${ }^{2}$ \\ ${ }^{1}$ Department of Zoology, University of Lagos, Akoka, Lagos State, Nigeria \\ ${ }^{2}$ Molecular Parasitology Research Laboratory, Department of Public Health and Epidemiolo- \\ gy, Nigerian Institute of Medical Research (NIMR), P.M.B. 2013, Yaba, Lagos State, Nigeria.
}

*Correspondence should be addressed to Susan I. Alexander: ijeomaalexander@gmail.com

Received 31st July 2021; Revised 11th October 2021; Accepted 3rd November 2021

(C) 2021 Alexander et al. Licensee Pan African Journal of Life Sciences an official publication of Faculty of Basic Medical Sciences, Ladoke Akintola University of Technology, Ogbomoso. This is an Open Access article distributed under the terms of the Creative commons Attribution License (https://creativecommons.org/licenses/BY/4.0), which permits unrestricted use, distribution, and reproduction in any medium, provided the original work is properly cited.

\begin{abstract}
Background: Schistosomiasis causes anaemia, stunting, and cognitive impairment in children, which impairs school performance. Government coordinated school-based preventive chemotherapy with donated praziquantel has been primarily used for schistosomiasis control in Ogun State, necessitating the need to monitor treatment coverage and its effect on schistosomiasis burden.

Methods: We screened 422 pupils aged 1-14 years old for Schistosoma haematobium in June 2018 using the filtration technique. KAP data and socio-demographic characteristics of participants were also recorded.

Results: Out of 422 screened pupils, 59 (14\%) tested positive using the filtration method. Peak prevalence (31.6\%) occurred in pupils under five years. Heavy infection intensity occurred in $3.4 \%$ of the infected population. KAP studies revealed that $55 \%$ knew schistosomiasis was linked to urinating blood. Symptoms experienced mainly were diarrhoea (44.6\%), stomach ache (29.7\%), and fever (13.5\%). Pipe-borne water $(48.2 \%)$, well water (28.7\%), and stream water (23.1\%) were the major sources of water for household chores. Investigations on excreta disposal showed that $70.3 \%$ defecated in latrines, $17.3 \%$ in the bush, and $12.4 \%$ in water closets. About $54.7 \%$ had contact with a stream, while $74.2 \%$ were dewormed in the last six months.

Conclusion: Children below five years old should be included in the Ogun State's Ministry of Health's treatment efforts. Health education should be intensified in the study areas because the population visiting streams and openly defaecating will continue undermining the Ogun State Ministry of Health's treatment efforts. Our study will serve as an evidence base for refining control measures and effectively utilising already scarce resources.
\end{abstract}

Keywords: Schistosoma haematobium, prevalence, KAP, children, Nigeria, disease intensity 


\subsection{INTRODUCTION}

Schistosomiasis is a devastating Neglected Tropical Disease (NTD), which leads to substantial morbidity and mortality in many low and middle-income countries [1]. It is caused by infectious trematode worms of the genus Schistosoma and ranks second only to malaria in terms of human suffering in affected countries [2]. There are over 240 million people infected and approximately 10,000 schistosomiasis-related deaths annually worldwide $[2,3]$. The Global Burden of Disease Study ranked Nigeria as having the highest number of schistosomiasis cases globally [4].

Infection is established through cercariae penetration of the skin during swimming in freshwater bodies containing snail intermediate hosts. Hence, improved sanitation and access to safe water are some of the world health organisation's recommended strategies for eliminating schistosomiasis [5]. Approximately twothirds of the schistosomiasis cases in sub-Saharan Africa are due to $S$. haematobium, the causative agent of urinary schistosomiasis [6]. Undernutrition and anaemia are some of the resultant morbidity of schistosomiasis [7]. Individuals with $S$. haematobium may also experience haematuria, dysuria, bladder-wall pathology, female genital sores (a high-risk factor for HIV) and hydronephrosis $[8,9]$.

Prevalence is often combined with the intensity of infection, also referred to as worm burden, commonly measured by the number of eggs per $10 \mathrm{ml}$ of urine and used as a measure to assess the epidemiological situation for a helminth infection [10]. Microscopic examination of eggs after urine filtration remains the standard urogenital schistosomiasis detection technique [5].

Praziquantel (PZQ $40 \mathrm{mg} / \mathrm{kg}$ ) is the only drug available for treatment $[2,11]$. It has been shown to be effective in decreasing worm burden, egg excretion, and accompanying symptoms of infection [12]. The widescale availability of PZQ is believed to reverse morbidity in schoolchildren, preventing as many as 70 million cases of haematuria, 8.5 million cases of splenomegaly, and 280,000 deaths annually [13]. Schistosomiasis deworming programs are typically school-based, with school teachers or community health workers distributing medicines to vulnerable children between 5-15 years of age. A height-based dose pole is used to determine the number of PZQ tablets to administer to children $[5,1]$.
In conjunction with the Ogun State Universal Basic Education Board (SUBEB), southwestern Nigeria, the Ogun State Ministry of Health has been carrying out mass treatment of pupils with $\mathrm{PZQ}$, at least once a year, depending on the availability of donated drugs, since 2017. The objective of this study was to assess the impact of the Ogun State Ministry of health's annual school-based schistosomiasis treatment efforts on the prevalence, morbidity, and level of awareness of schistosomiasis in the study areas. Findings from the study will assist the Ogun state Ministry of Health on effective and targeted use of praziquantel and health education strategies.

\subsection{METHODOLOGY}

\subsection{Study Population}

This study was conducted at Ogun State, one of the 36 states of the Federal Republic of Nigeria. It is located in the southwestern part of the country within longitude $2^{\circ}$ $45^{\prime} \mathrm{E}$ and $3^{\circ} 55^{\prime} \mathrm{E}$ and latitude $7^{\circ} 01^{\prime} \mathrm{N}$ and $7^{\circ} 18^{\prime} \mathrm{N}$. Ogun state is divided into 20 administrative areas known as local government areas (LGAs) and is one of the few states with a formal control programme for schistosomiasis in Nigeria. Furthermore, there are 1,314 public primary schools with an average of 100 pupils enrolled in each school. Obafemi Owode, Sagamu, and Ijebu-East LGAs were selected for the study because they are among the LGAs where the pilot formal control programme was conducted. Using the cluster sampling technique, four public primary schools were selected, with at least one in each LGA and 100 pupils per school. All consented pupils participated in the study. Public schools in rural areas were selected because of their remoteness and proximity to freshwater habitats.

\subsection{Study Design}

The study design was cross-sectional and school-based. Pupils aged 1-14 years with parental consent were recruited into the study. Of the available 485 pupils, only 422 participated in the study. Each pupil was given a sterile $200 \mathrm{ml}$ specimen bottle with a unique code corresponding to demographic data, including name, surname, LGA, school name, age, sex, weight, and height. Heights and weights were determined using a metre rule and weighing scale respectively. Pupils were advised to collect midstream urine. Caregivers assisted younger children in collecting urine specimens. Urine samples were collected between 10 a.m and 2 p.m for 
three days. Four drops of formol saline were mixed into each urine sample before being transported to the Nigerian Institute of Medical Research Lagos and stored at $-20^{\circ} \mathrm{C}$ until processing. Data were collected from 364 willing pupils in the study areas using a structured questionnaire. The questions were related to age, gender, educational level and occupation of parents, knowledge of infection, water contact activities and personal hygiene of respondents. Respondents were interviewed in English, Yoruba, and Pidgin English.

\subsection{Ethics Statement}

Ethical clearance and approval were obtained from the Institutional Review Board of the Nigerian Institute of Medical Research Lagos (IRB/17/007), Ogun State Ministry of Health, Ogun State Universal Basic Education Board (SUBEB), and the Local Government Education Authority (LGEAs) in the study areas. Informed consent was obtained from parents or guardians of the school pupils with the help of the headteachers and officers of the LGEAs. Children with no parental consent were excluded.

\subsection{Sample Preparation}

The filtration technique was used to detect $S$. haematobium ova in urine [14]. A drop of Eosin stain was gently mixed with $10 \mathrm{ml}$ of each urine sample to enhance staining. About $10 \mathrm{ml}$ of urine sample was flushed with a sterile syringe through a polycarbonate filter membrane, followed by staining with $20 \mathrm{ml}$ of Lugol's iodine solution. A drop of Ninhydrin solution was added to each filter membrane to fix the schistosome ova [15]. The filter membranes were air-dried and examined under the light microscope using $\times 10$ and $\times 40$ objectives, and the number of eggs per filter was recorded as light infection if $<50$ eggs and heavy if $\geq 50$ eggs [5].

\subsection{Statistical Analysis}

The data were analysed using Statistical Package for Social Sciences (Windows version 16.0; SPSS Inc, Chicago, IL, US) and Microsoft Excel (2013) with the application of a chi-square test. Descriptive analysis was used to express gender occurrence and mean age, while the prevalence of infection was expressed in percentage. The difference in the prevalence of infection between the variables was determined using a chi-square test at a $95 \%$ confidence interval. P-values less than 0.05 were considered statistically significant

\subsection{RESULTS}

Of the 422 participants, 59(14\%) were positive for $S$. haematobium (Table 1). There were more male participants $(56 \%)$ than females $(44 \%)$. While more females $(16.1 \%)$ were infected, the difference was not statistically significant $(\mathrm{p}=0.259)$. Obafemi-owode was the most infected local government area (15.9\%), followed by Saga$\mathrm{mu}(13.9 \%)$. Ijebu-East had the least number of infected pupils $(13.0 \%)$. There was no significant difference in prevalence across Local Government Areas $(p=0.781)$. The mean age was 8.12. S. haematobium infection was most prevalent in pupils under five years of age (31.6\%). The difference in prevalence among age groups was statistically significant $(\mathrm{p}=0.049)$.

Table 1. Prevalence of Urogenital Schistosomiasis by Gender, LGA and Age

\begin{tabular}{|c|c|c|c|}
\hline Gender & $\begin{array}{l}\text { Number } \\
\text { examined }\end{array}$ & $\begin{array}{l}\text { Number positive } \\
\text { for S. haematobi- } \\
\text { um ova }\end{array}$ & $\chi^{2}$ \\
\hline $\begin{array}{l}\text { Male } \\
\text { Female }\end{array}$ & $\begin{array}{l}236(55.9 \%) \\
186(44.1 \%)\end{array}$ & $\begin{array}{l}29(12.3 \%) \\
30(16.1 \%)\end{array}$ & $\begin{array}{l}\chi^{2}=1.276^{\mathrm{a}} \mathrm{p}>0.05 \\
(\mathrm{p} \text { value }=0.259)\end{array}$ \\
\hline $\begin{array}{l}\text { Total } \\
\text { LGA }\end{array}$ & 422 & 59 & \\
\hline $\begin{array}{l}\text { Sagamu } \\
\text { Ijebu- } \\
\text { East } \\
\text { Obafemi- } \\
\text { Owode } \\
\text { Total }\end{array}$ & $\begin{array}{l}122(28.9 \%) \\
193(45.7 \%) \\
107(25.4 \%) \\
422\end{array}$ & $\begin{array}{l}17(13.9 \%) \\
25(13.0 \%) \\
17(15.9 \%) \\
59\end{array}$ & $\begin{array}{l}\chi^{2}=0.493^{\mathrm{a}} \mathrm{p}>0.05 \\
(\mathrm{p} \text { value }=0.781)\end{array}$ \\
\hline $\begin{array}{l}\text { Age } \\
\text { group } \\
\text { (Year) } \\
0-4 \\
5-9 \\
10-14\end{array}$ & $\begin{array}{l}19(4.5) \\
136(32.2) \\
267(63.3 \%)\end{array}$ & $\begin{array}{l}6(31.6 \%) \\
21(15.4 \%) \\
32(12.0 \%)\end{array}$ & $\begin{array}{l}\chi^{2}=6.018^{\mathrm{a}} \mathrm{p}<0.05 \\
(\mathrm{p} \text { value }=0.049)\end{array}$ \\
\hline
\end{tabular}

Heavy intensity classified as $\geq 50 \mathrm{~S}$. haematobium ova per $10 \mathrm{ml}$ of urine infection was detected in only 2 pupils (3.4\% of the infected population); one from Ijebu-East and the other from Obafemi-Owode (Table 2). The only two pupils with heavy infection was a male in the 5-9 age group and a female in the 10-14 age group (Table 3).

Only $364(86.3 \%)$ out of the 422 pupils in the study population took part in the questionnaire survey (Table 4). About $54 \%$ of respondents were male, while $46 \%$ were female. The majority of the respondents $(61.3 \%)$ were between 10-14 years old, Christians (82\%), had between one to four siblings $(50 \%)$, and had parents with some 
Table 2. Intensity of Urogenital Schistosomiasis Stratified by LGA

\begin{tabular}{llll}
\hline LGA & Light & Heavy & $\begin{array}{l}\text { Total } \\
\text { (No.) }\end{array}$ \\
\hline Sagamu & 17 & 0 & 17 \\
Ijebu-East & 23 & 1 & 24 \\
$\begin{array}{l}\text { Obafemi- } \\
\text { Owode }\end{array}$ & 17 & 1 & 18 \\
Total & 57 & 2 & 59 \\
\hline
\end{tabular}

Table 3. Intensity of infection by age and sex

\begin{tabular}{lllllll}
\hline $\begin{array}{l}\text { Age } \\
\text { group } \\
\text { (Years) }\end{array}$ & \multicolumn{2}{l}{ Male } & & \multicolumn{5}{c}{ Female } \\
\cline { 2 - 7 } & No & Light & Hea & No. & Light & Heavy \\
& 2 & 2 & 0 & 4 & 4 & 0 \\
$0-4$ & 2 & vy & & \\
$5-9$ & 8 & 7 & 1 & 13 & 13 & 0 \\
$10-14$ & 19 & 20 & 0 & 13 & 12 & 1 \\
\hline
\end{tabular}

form of formal education (99.5\%). Disease awareness showed that $54 \%$ of respondents know what schistosomiasis is (urinating blood). Symptoms experienced mainly were diarrhea $(44.6 \%)$, stomachache $(29.7 \%)$, and fever (13.5\%). Concerning water use, $48.2 \%$ fetch water for household chores from taps, $28.7 \%$ from wells, and $23.1 \%$ from rivers/streams. Furthermore, $70.3 \%$ defecate in latrines, $17.3 \%$ in the bush, while $12.4 \%$ use water closets. Over $50 \%$ of the responders had contact with water bodies in the last six months, and about $74.2 \%$ were dewormed of $S$. haematobium within the last six months. About 25 students out of the 63 children that defaecated in the open were positive for S. haematobium. Of the 270 dewormed children, 5 (2\%) were positive, while 21 out of the 209 children who had contact with a water body were positive for $S$. haematobium as well (Table 4).

\subsection{DISCUSSION}

In this study, urine filtration and microscopy were used to detect $S$. haematobium ova in 422 school-age children attending state-owned schools, namely: Wesley primary school Gbara, and St Mark Primary School Iwelepe (Sagamu); St Joseph Primary school Ogbere (Ijebu-East) and lastly St John Anglican school situated at Obafemi-
Owode LGA. We recorded an overall prevalence of $14 \%$

Table 4. Knowledge Attitude and Practice (KAP) Survey

\begin{tabular}{|c|c|c|c|}
\hline Variables & $\mathbf{N}$ & $\%$ & $\begin{array}{l}\text { No. Posi- } \\
\text { tive }\end{array}$ \\
\hline \multicolumn{4}{|l|}{ Gender } \\
\hline Males & 197 & 54 & 14 \\
\hline $\begin{array}{l}\text { Females } \\
\text { Total }\end{array}$ & $\begin{array}{l}167 \\
364\end{array}$ & $\begin{array}{l}46 \\
100\end{array}$ & 19 \\
\hline $\begin{array}{l}\text { Age groups (years) } \\
0-4 \\
5-9 \\
10-14 \\
\text { Total }\end{array}$ & $\begin{array}{l}9 \\
120 \\
222 \\
362\end{array}$ & $\begin{array}{l}2.5 \\
33.1 \\
61.3 \\
100\end{array}$ & $\begin{array}{l}2 \\
10 \\
19 \\
31\end{array}$ \\
\hline \multicolumn{4}{|l|}{ Religion } \\
\hline Islam & 61 & 17 & 4 \\
\hline Traditional & 2 & 1 & 0 \\
\hline Total & 364 & & 33 \\
\hline $\begin{array}{l}\text { Educational level of parents } \\
\text { Educated (at least primary educa- } \\
\text { tion) }\end{array}$ & 344 & 95 & 23 \\
\hline $\begin{array}{l}\text { Non educated (no formal educa- } \\
\text { tion) }\end{array}$ & 19 & 5 & 9 \\
\hline \multicolumn{4}{|l|}{ Number of siblings } \\
\hline $1-4$ & 180 & 50 & 19 \\
\hline $\begin{array}{l}5-8 \\
9-12 \\
\text { Total }\end{array}$ & $\begin{array}{l}162 \\
18 \\
360\end{array}$ & $\begin{array}{l}45 \\
5\end{array}$ & $\begin{array}{l}10 \\
1\end{array}$ \\
\hline $\begin{array}{l}\text { Do you know schistosomiasis is } \\
\text { a disease } \\
\text { Yes } \\
\text { No } \\
\text { Total } \\
\text { Symptoms experienced }\end{array}$ & $\begin{array}{l}54 \\
21 \\
75\end{array}$ & $\begin{array}{l}72 \\
28\end{array}$ & $\begin{array}{l}5 \\
7 \\
12\end{array}$ \\
\hline $\begin{array}{l}\text { Fever } \\
\text { Stomach ache } \\
\text { Diarrhea }\end{array}$ & $\begin{array}{l}10 \\
22 \\
33\end{array}$ & $\begin{array}{l}13.5 \\
29.7 \\
44.6\end{array}$ & $\begin{array}{l}0 \\
1 \\
5\end{array}$ \\
\hline $\begin{array}{l}\text { Blood in urine } \\
\text { Blood in stool } \\
\text { Total }\end{array}$ & $\begin{array}{l}5 \\
4 \\
74\end{array}$ & $\begin{array}{l}6.8 \\
5.4\end{array}$ & $\begin{array}{l}3 \\
0 \\
9\end{array}$ \\
\hline \multicolumn{4}{|l|}{$\begin{array}{l}\text { Where do you fetch water for } \\
\text { household chores? }\end{array}$} \\
\hline River/Stream & 84 & 23.1 & 19 \\
\hline Well & 104 & 28.7 & 2 \\
\hline Tap & 175 & 48.2 & 12 \\
\hline Total & 363 & & 33 \\
\hline \multicolumn{4}{|l|}{ Where do you defecate? } \\
\hline $\begin{array}{l}\text { Bush } \\
\text { Latrine }\end{array}$ & $\begin{array}{l}63 \\
256\end{array}$ & $\begin{array}{l}17.3 \\
70.3\end{array}$ & $\begin{array}{c}25 \\
5\end{array}$ \\
\hline $\begin{array}{l}\text { Water closet } \\
\text { Total }\end{array}$ & $\begin{array}{l}45 \\
364\end{array}$ & 12.4 & $\begin{array}{l}2 \\
33\end{array}$ \\
\hline \multicolumn{4}{|l|}{$\begin{array}{l}\text { Any contact with a water body } \\
\text { in the last } 6 \text { months? }\end{array}$} \\
\hline $\begin{array}{l}\text { Yes } \\
\text { No }\end{array}$ & $\begin{array}{c}209 \\
155\end{array}$ & $\begin{array}{l}57.4 \\
42.6\end{array}$ & $\begin{array}{l}21 \\
12\end{array}$ \\
\hline Total & 364 & & 33 \\
\hline \multicolumn{4}{|l|}{$\begin{array}{l}\text { Have you taken worm medicine } \\
\text { in the last } 6 \text { months }\end{array}$} \\
\hline Yes & 270 & 74.2 & 5 \\
\hline No & 94 & 25.8 & 28 \\
\hline Total & 364 & & 33 \\
\hline
\end{tabular}


(14 \% in Sagamu, 13\% in Ijebu-East, and 16\% at Obafemi-Owode). This is higher than the previous prevalence of $0 \%$ Oluwole et al., [16] reported in Sagamu (zero prevalence), $8.5 \%$ in Ijebu-East, and $6.3 \%$ in Obafemi-Owode. However, Oluwole et al., [16] admitted that schistosomiasis prevalence in their study might have been underestimated because areas close to water bodies were skipped. Furthermore, the prevalence in this study is moderate by WHO standards [1], but this is also significant because helminth parasite distributions are highly aggregated, with most worms harboured by few in a population. These few persons continue to serve as reservoirs for the perpetuation of infection in the community [17]. The State Ministry of Health may need to consistently monitor drug coverage and individual compliance during successive treatment rounds.

Regarding gender, although more than half of the participants were males, peak prevalence surprisingly occurred in females, in contrast with studies by Hajiss et al., [18] but agreed with studies by Kayuni et al., [19]. In our study, gender did not significantly influence the rate of infection.

Peak prevalence observed in the 0-4 age group is in line with a study by Ndassi et al., [20] but contrasts with Abdulkareem et al., [21]. High prevalence may be attributed to the limited number of participants in the age group or the fact that treatment is administered only to pupils between ages 5-14 years, due to the non-availability of pediatric praziquantel for preschool children [1]. The prevalence between age groups in this study was statistically significant $(\mathrm{P}>0.05)$. Agnew-Blais et al., [22] made a similar observation in Zambia, but this was in contrast with what was observed by Kayuni et al., [19] in Malawi.

The intensity of $S$. haematobium in this study described the parasite burden and was measured by the number of eggs excreted per $10 \mathrm{ml}$ of urine. The overall rate of light intensity infections was higher than heavy intensity infections indicating that only a few children were carriers of heavy parasite load. This is in agreement with the findings that helminth infections have an aggregated distribution in endemic communities, such that a small proportion of hosts are heavily infected [23,24]. Infected individuals are likely to re-introduce infectious material into the environment, perpetuate transmission, and increase incidence among those successfully treated.

Knowledge, Attitude, and Practice (KAP) of a population regarding infection are essential in planning, implementing, and evaluating interventions [25]. A KAP survey can identify knowledge gaps, cultural beliefs, or behavioural patterns, which help identify needs, problems, and barriers in programme delivery and solutions for improving the quality and accessibility of services. Our findings revealed that the children know that schistosomiasis (urinating blood) is a disease with fewer children fetching water from streams/rivers (23\%) and more children utilising latrines $(70 \%)$ rather than defaecating in the bush. This may be linked to the health education administered by the Ogun State Ministry of Health officials during treatment campaigns. However, children who defaecate in the bush or regularly have contact with water bodies will be a source of infection to the other children.

In conclusion, our study revealed that urogenital schistosomiasis is still endemic in the study areas. Health education needs to be intensified to close the knowledge gaps and promote zero contact with freshwater bodies. We also advocate for the provision and maintenance of potable water and toilet facilities, especially in remote areas, and close monitoring of drug distribution to ensure every child has access to treatment.

\section{Funding}

This research work did not receive funding from any organization.

\section{Acknowledgments}

We thank the staff of the Public Health Unit of the Ogun State Ministry of Health and the Ogun State Universal Basic Education for providing treatment data and advisory support during our study.

\section{Conflicts of Interest}

The authors declare no competing interests.

\section{Authors' Contributions}

SIA conceived and designed the study, contributed to data collection, data analysis tools, analysis of data and manuscript writing. TSN contributed to data collection and analysis of data. PVG contributed to data collection, data analysis tools and analysis of data. ETI contributed to study design, data analysis tools, supervised the study and proof-read manuscript. OPA contributed to study design, data analysis tools and manuscript writing. All authors approved the final copy of the manuscript 


\section{References}

1. WHO. Preventive chemotherapy in human helminthiasis: coordinated use of anthelminthic drugs in control interventions: a manual for health professionals and programme managers. World Health Organization 2006; p. 41 ISBN: 9789241547103.

2. Inobaya MT, Olveda RM, Chau TN, Olveda DU, Ross AG. Prevention and control of schistosomiasis: a current perspective. Res Rep Trop Med. 2014;5:65.

3. Naghavi M, Abajobir AA, Abbafati C, Abbas KM, AbdAllah F, Abera SF, et al. Global, regional, and national agesex specific mortality for 264 causes of death, 1980-2016: a systematic analysis for the Global Burden of Disease Study 2016. Lancet 2017; 390(10100): 1151-1210.

4. Herricks JR, Hotez PJ, Wanga V, Coffeng LE, Haagsma JA, Basáñez MG, et al. The global burden of disease study 2013: What does it mean for the NTDs? PLoSNegl Trop Dis 2017;11(8): e0005424.

5. WHO. Prevention and control of schistosomiasis and soiltransmitted helminthiasis: report of a WHO expert committee (No. 912). WHO Expert Committee on the Control of Schistosomiasis, and World Health Organization; 2002.

6. Hotez PJ, Kamath A. Neglected tropical diseases in subSaharan Africa: review of their prevalence, distribution, and disease burden. PLoSNegl Trop Dis 2009;3(8): e412.

7. Coutinho HM, Acosta LP, McGarvey ST, Jarilla B, Jiz M, Pablo A, Su L, Manalo DL, Olveda RM, Kurtis JD, Friedman JF. Nutritional status improves after treatment of schistosoma japonicum-infected children and adolescents. J Nutr 2006;136(1): 183-188.

8. van der Werf MJ, de Vlas SJ, Brooker S, Looman CW, Nagelkerke NJ, Habbema JD, et al. Quantification of clinical morbidity associated with schistosome infection in subSaharan Africa.Acta Trop. 2003;86(2-3):125-39.

9. Kjetland EF, Ndhlovu PD, Gomo E, Mduluza T, Midzi N, Gwanzura L, et al. Association between genital schistosomiasis and HIV in rural Zimbabwean women. Aids 2006; 20(4): 593-600.

10. Hotez PJ, Brindley PJ, Bethony JM, King CH, Pearce EJ, Jacobson J. Helminth infections: the great neglected tropical diseases. J. Clin. Invest. 2008;118(4):1311-1321.

11. Kabuyaya M, Chimbari MJ, Manyangadze T, Mukaratirwa, S. Efficacy of praziquantel on Schistosoma haematobium and re-infection rates among school-going children in the Ndumo area of uMkhanyakude district, KwaZulu-Natal, South Africa. Infect. Dis. Poverty 2017; 6(1): 1-9.

12. Lamberton PH, Faust CL, Webster JP. Praziquantel de- creases fecundity in Schistosoma mansoni adult worms that survive treatment: evidence from a laboratory life-history trade-offs selection study. Infect. Dis. Poverty 2017;6(1), 111.

13. Hotez PJ, Engels D, Fenwick A, Savioli L. Africa is desperate for praziquantel. Lancet. 2010;376(9740):496-8.

14. WHO. The control of schistosomiasis: second report of the WHO Expert Committee [meeting held in Geneva from 815 November 1991]. World Health Organization,https:// apps.who.int/iris/handle/10665/37115;1993 [last accessed 16 July 2020].

15. Pugh RNH, Gilles HM. Malumfashi endemic diseases research project, III. Urinary schistosomiasis: a longitudinal study.Ann Trop Med Parasitol. 1978;72(5), 471-482.

16. Oluwole AS, Adeniran AA, Mogaji HO, Olabinke DB, Abe EM, Bankole SO, et al. Prevalence, intensity and spatial codistribution of schistosomiasis and soil transmitted helminths infections in Ogun state, Nigeria.Parasitol. Open. $2018 ; 4$.

17. Savioli L, Albonico M, Daumerie D, Lo NC, Stothard JR, Asaolu S, TchuemTchuenté LA, Anderson RM. Review of the 2017 WHO Guideline: Preventive chemotherapy to control soil-transmitted helminth infections in at-risk population groups. An opportunity lost in translation. PLOS Negl. Trop. Dis.. 2018;12(4):e0006296.

18. Hajiss K, Abd-Elhafiz MA, Eshag HA, Alfadel A, Nahied E, Dahab R, Ali SA, Mohammed M, Gaafar M, Mohamed $Z$. Prevalence of schistosomiasis and associated risk factors among school children in Um-Asher Area, Khartoum, Sudan. BMC Res. Notes 2018; 11(1): 779.

19. Kayuni S, Peeling R, Makaula P. Prevalence and distribution of Schistosoma haematobium infection among school children living in southwestern shores of Lake Malawi.Malawi Med J 2017;29(1): 16-23.

20. Ndassi VD, Anchang-Kimbi JK, Sumbele IUN, Wepnje GB, Kimbi HK. Prevalence and Risk Factors Associated with S. haematobium Egg Excretion during the Dry Season, Six Months following Mass Distribution of Praziquantel (PZQ) in 2017 in the Bafia Health Area, South West Region Cameroon: A Cross-Sectional Study.J Parasitol Res 2019;2019

21. Abdulkareem BO, Habeeb KO, Kazeem A, Adam, AO, Samuel, UU . Urogenital schistosomiasis among schoolchildren and the associated risk factors in selected rural communities of Kwara state, Nigeria. J. Trop. Med. 2018;6: 913-918 
22. Agnew-Blais, J, Carnevale J, Gropper A, Shilika E, Bail R, Ngoma M. Schistosomiasis haematobium prevalence and risk factors in a school-age population of peri-urban Lusaka, Zambia. J Trop Pediatrics 2010;56(4): 247-253.

23. Shehata MA, Chama MF, Funjika E. Prevalence and intensity of Schistosoma haematobium infection among schoolchildren in central Zambia before and after mass treatment with a single dose of praziquantel. Trop Parasitol, 2018;8(1), 12.
24. Amuta EU, Houmsou RS. Prevalence, intensity of infection and risk factors of urinary schistosomiasis in preschool and school aged children in Guma Local Government Area, Nigeria. Asian Pac. J. Trop. Med. 2014;7 (1):34-39.

25. WHO. Advocacy, communication and social mobilization for TB control: a guide to developing knowledge, attitude and practice surveys. No. WHO/HTM/STB/2008.46. World Health Organization 2008. 